\title{
MODIFIED LAUTENBACH TECHNIQUE AND EXTERNAL FIXATION AS A TREATMENT FOR INFECTED NON-UNION OF THE SUBTROCHANTER FEMUR: A CASE REPORT
}

\author{
Mouli Edward ${ }^{1}$, Teddy Heri Wardhana ${ }^{1}$, Erfan Nasrullah ${ }^{2}$ \\ ${ }^{1}$ Staff of Orthopaedic and Traumatology Department, Faculty of Medicine, Universitas \\ Airlangga/Dr Soetomo General Hospital, Surabaya \\ ${ }^{2}$ Resident of Orthopaedic and Traumatology Department, Faculty of Medicine, Universitas \\ Airlangga/Dr Soetomo General Hospital, Surabaya \\ *Corresponding Author: Erfan Nasrullah, Resident of Orthopaedic and Traumatology \\ Department, Faculty of Medicine, Universitas Airlangga/Dr Soetomo General Hospital, Jl. \\ Prof. Dr. Moestopo 6-8, Surabaya. \\ E-mail: erfan.ortho@gmail.com
}

\begin{abstract}
ABSTRAK
Infected non union masih merupakan kasus orthopaedi yang sulit untuk ditangani. Sampai saat ini tidak ada protokol tunggal yang diterima secara luas sebagai protokol tatalaksana infected non union femur. Lokasi infeksi pada subtrochanter femur memberikan tantangan ekstra karena pada area tersebut terdapat gaya tension dan kompresi yang besar. Pada laporan ini dilakukan evaluasi terhadap perempuan usia 20 tahun dengan infeksi subtrochanter femur kanan pasca open reduction internal fixation (ORIF) dengan angle blade plate (ABP) $95^{\circ}$. Dilakukan tindakan operasi satu tahap berupa implant removal, debridement, fiksasi eksternal definitif, dan pemberian antibiotik secara lokal melalui modifikasi teknik Lautenbach. Empat tahun pascatrauma, pasien dapat mobilisasi mandiri tanpa alat bantu, tidak didapatkan rekurensi infeksi, dan Haris Hip Score 91 (excellent). Berdasarkan hasil yang diperoleh pada kasus ini, fiksasi eksternal definitif dan modifikasi teknik Lautenbach dalam satu tahap operasi dapat menjadi salah satu pilihan terapi pada kasus infected non union subtrochanter femur.
\end{abstract}

Kata kunci:infected non-union, subtrochanter, operasi satu tahap, fiksasi eksternal, teknik lautenbach

\begin{abstract}
Infected non-union is still a challenging orthopedic case to treat. Up until present day, there is no any established protocol to treat infected non-union of femur. Infection at subtrochanter femur specifically poses extra challenge as aforementioned location is affected by great tension and compression force. In this report, we present a 20 -yo woman with infected subtrochanter femur following open reduction internal fixation (ORIF)with angle blade plate (ABP) $95^{\circ}$. One stage surgery was performed involving implant removal, debridement, definite external fixation, and antibiotic delivery using modified Lautenbach technique. Four years after trauma, the patient was capable of independent mobilization without aid. No infection recurrence was found, and Haris Hip Score was 91 (excellent). Based on the result of this case, definite external fixation and modified Lautenbach technique in one stage surgery can be a viable option in treating infected non-union of subtrochanter femur.
\end{abstract}

Keyword: infected non-union, subtrochanter, one-stage surgery, external fixation, Lautenbach technique 


\section{PENDAHULUAN}

Infected non union masih merupakan kasus orthopaedi yang sulit untuk ditangani. Infeksi kronis merupakan kasus yang mahal, sulit diterapi dan hasilnya seringkali tidak memuaskan. ${ }^{1}$ Sampai saat ini belum ada protokol tunggal penanganan infected non union femur yang diterima secara luas. ${ }^{2}$

Salah satu inovasi terapi infeksi tulang dikembangkan oleh Weber dan Lautenbach pada 1986 dengan debridement radikal dan eksisi jaringan infeksi, diikuti dengan debridement endoesteoum dan pemberian antibiotik konsentrasi tinggi secara lokal melalui sistem irigasi menggunakan selang yang diletakkan di dalam medulla. ${ }^{3}$ Teknik ini dimodifikasi oleh Johnson dengan meletakkan sistem irigasi antibiotik di luar medulla pada kasus infeksi fraktur clavicula. ${ }^{4}$

Infeksi pada fraktur subtrochanter femur memiliki tantangan yang lebih besar karena pada area tersebut gaya tension dan kompresi yang diterima merupakan yang terbesar dibanding seluruh tulang yang ada pada tubuh. Konstruksi fiksasi pada area ini harus mampu menahan gaya berlipat-lipat berat tubuh. $^{5}$

Fiksasi eksternal umumnya tidak direkomendasikan sebagai fiksasi definitif pada area subtrochanter. Akan tetapi pada kasus infeksi khususnya di negara berkembang, fiksasi eksternal seringkali digunakan sebagai fiksasi definitif. ${ }^{6}$

Pada kasus ini kami melaporkan satu pasien dengan infected non union subtrochanter femur yang berhasil pulih dengan fiksasi eksternal definitif yang dikombinasi dengan modifikasi teknik Lautencbach dan dievaluasi hingga 4 tahun pascatrauma.

\section{LAPORAN KASUS}

Seorang perempuan berusia 20 tahun datang dengan keluhan nyeri, demam, malaise, disertai produksi nanah yang keluar dari bekas luka operasi pemasangan implan pada paha kanan yang memberat sejak satu bulan yang lalu. Hasil laboratorium menunjukkan peningatan penanda infeksi white blood count (WBC) $11,6 \times 10^{3} / \mu 1$, laju endap darah (LED) 60 $\mathrm{mm} / \mathrm{jam} \quad(0-20), \quad$-reactive protein $(\mathrm{CRP})>120 \quad \mathrm{mg} / \mathrm{L} \quad(<6)$. Radiologis menunjukkan implan angle blade plate (ABP) $95^{\circ}$ masih dalam posisi baik, tidak ada tanda loosening, namun didapatkan bone gap pada fragmen fraktur.

Tiga bulan sebelumnya, pasien mengalami kecelakaan sepeda motor menabrak sepeda motor lain dalam kecepatan tinggi hingga pasien terlontar dan menghantam tiang listrik di tengah jalan. 

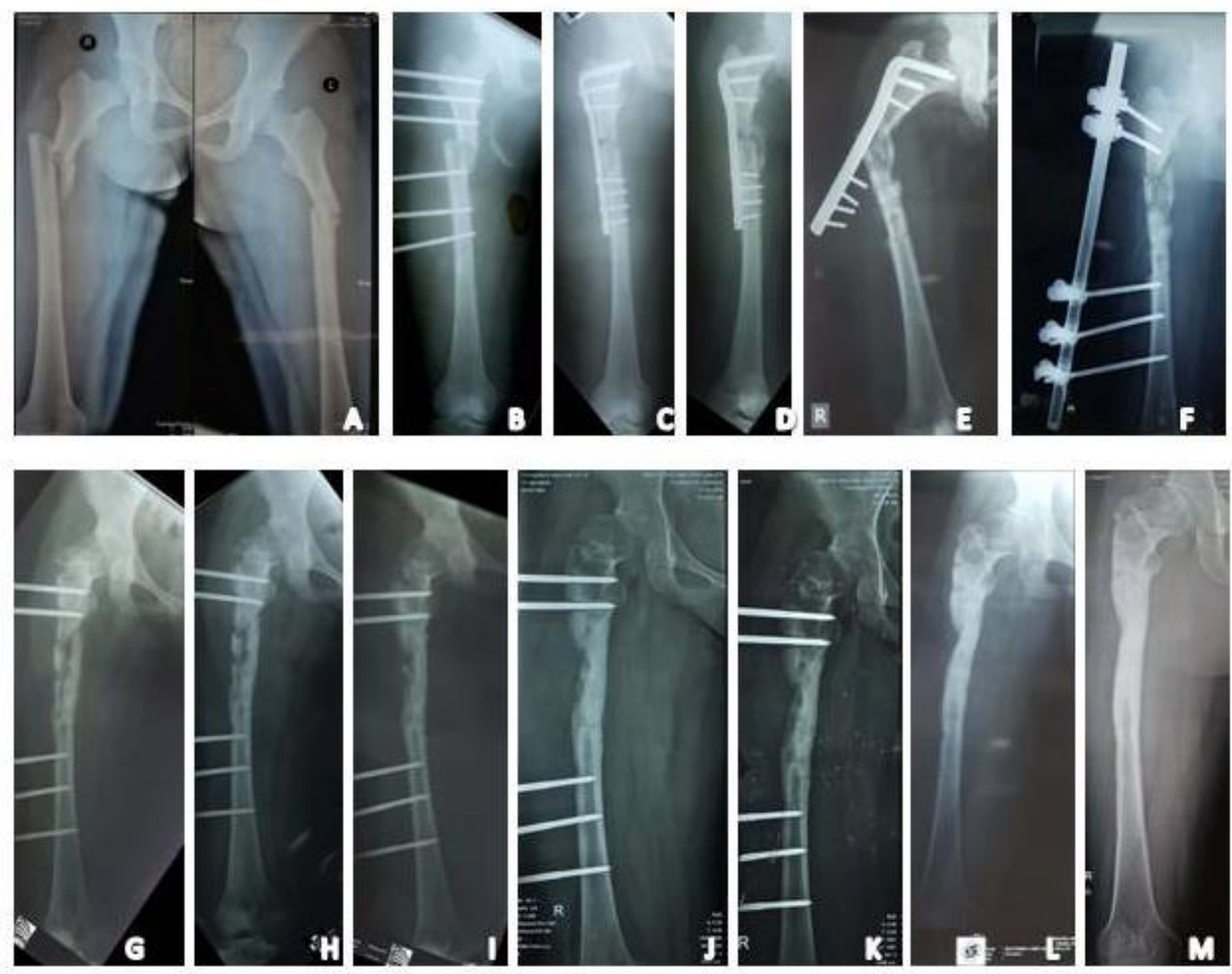

Gambar 1. Serial evaluasi radiologi A) awal trauma, B) hasil damage control, C) fiksasi definitif awal dengan $\mathrm{ABP} 95^{\circ}$, D) setelah operasi debridement pertama, E) fixation failure 8 bulan pascatrauma, F) post op teknik modifikasi Lautenbach dan fiksasi eksternal, G) evaluasi 2 bulan, H) evaluasi 3 bulan, I) evaluasi 6 bulan, J) evaluasi 10 bulan, K) evaluasi 13 bulan, L) post affiksasi eksternal bulan ke-16, M) evaluasi 31 bulan

Pasien mengalami patah tulang tertutup pada subtrochanter kedua femur, sacroilliac joint disruption kiri dan penurunan kesadaran akibat fat emboli syndrome. Pasien kemudian mendapatkan tindakan damage control dengan fiksasi eksternal femur bilateral dan perawatan di ICU. Setelah itu, dilanjutkan dengan fiksasi defintif berupa screwing sacroilliac joint kiri dan ORIF ABP $95^{\circ}$ femur kanan dan kiri pada saat kondisi pasien stabil.
Akhirnya, pada pasien ini dilakukan intervensi bedah setelah pemberian antibiotik selama dua minggu. Pada saat operasi didapatkan kantung pus disekitar tulang, disertai fistel, jaringan fibrotik dan non union femur, dengan implan masih terpasang stabil. Dilakukan pengambilan sampel kultur, debridement, kortikotomi, penambahan bovine bone graft, dan implan ABP yang terpasang sebelumnya dipertahankan. Kondisi klinis membaik dan tidak didapatkan lagi rembesan nanah dari 
luka operasi. Pasien kemudian dipulangkan dan kontrol berkala melalui poliklinik.

Empat bulan setelah debridement, pasien datang kembali dengan keluhan nyeri hebat pada paha kanan. Hasil radiologi menunjukkan fixation failure berupa pull out seluruh screw dari fragmen distal fraktur. Hasil pemeriksaan penanda infeksi tinggi. Tidak ada riwayat trauma, hanya saja pasien mencoba mobilisasi di rumah dengan merangkak.

Dilakukan operasi yang kedua. Pada operasi kedua ini dilakukan pengambilan sampel kultur, implant removal, debridement dan eksisi jaringan nekrotik pada daerah subcutis, fascia, dan otot, serta pemberian antibotik secara terlokalisir dengan teknik modifikasi Lautenbach.

Teknik modifikasi Lautenbach terdiri dari reseksi fragmen ujung tulang yang non union, kemudian dilanjutkan dengan intramedullary reaming untuk membersihkan jaringan endoseteum yang terinfeksi. Pada akhir reaming, medullary canal dan jaringan sekitarnya diirigasi dengan normal saline.

Kedua ujung tulang yang telah direseksi didekatkan agar terjadi kontak dengan tetap menjaga alignment. Fragmen tulang kemudian difiksasi dengan fiksasi eksternal dari bahan stainless steel dengan 2 screw di fragmen proksimal dan 3 screw di fragmen distal dengan arah tegak lurus dengan aksis tulang femur. Setelah itu dihubungkan dengan rod.

Dua selang drain dimasukkan masingmasing dari sisi proksimal dan distal pada level submusculer dengan ujung drain berada di dekat garis fraktur. Luka kemudian dijahit aproksimasi.

Pada teknik Lautenbach yang orisinal digunakan dua selang double lumen yang diletakkan di dalam medulla. Kemudian tulang difiksasi menggunakan gips atau traksi. $^{3}$

Pascaoperasi larutan antibiotik amikasin diberikan melalui salah satu selang dan drainase melalui saluran lain dengan menggunakan vakum aktif. Antibiotik diberikan selama satu minggu. Pada hasil kultur didapatkan biakan Enterobacter cloacae yang sensitif dengan amikacin.

Pasien kemudian dipulangkan dengan obat antibiotik oral rifampisin $450 \mathrm{mg} / \mathrm{hari}$, mobilisasi non-weight bearing dan evaluasi melalui rawat jalan.

Bridging callus mulai tampak jelas pada bulan ketiga pasca debridement dan evaluasi berkala menunjukkan callus semakin tebal. Pasien mulai latihan mobilisi partial weight bearing setelah bulan kelima dengan mempertimbangkan pertumbuhan callus pada sisi kanan dan union dari fraktur femur kiri.

Pada saat evalausi di poliklinik didapatkan problem subluksasi sendi 


\section{Laporan Kasus}

Vol 8 No. 1, April 2019

ISSN 2460-8742

http://journal.unair.ac.id/ORTHO@journal-orthopaedi-and-traumatology-surabaya-media-104.html

panggul kanan. Pada kondisi ini dilakukan observasi terlebih dulu sambil menunggu union femur kanan. Antibiotik oral rifampisin $450 \mathrm{mg} /$ hari tetap diteruskan hingga union.

Enam belas bulan setelah operasi, fiksasi eksternal dilepas dilanjutkan dengan latihan mobilisasi dan ruang gerak sendi yang lebih agresif. ABP pada femur kiri yang telah union dan satu screw sacroiliac joint yang mengalami loosening dilepas 3 tahun pascaoperasi. Serial evaluasi radiologis ditunjukkan pada Gambar 1.

Evaluasi klinis empat tahun pascatrauma (tiga tahun pascaoperasi eksternal fikasi) terlihat seperti pada Gambar 2. Pasien dapat mobilisasi mandiri tanpa alat bantu dengan short leg gait minimal akibat discrepancy sebesar $2 \mathrm{~cm}$. Nyeri dirasakan hanya kadang-kadang saat aktivitas berat namun tidak mengganggu kegiatan sehari-hari. Gerak fleksi sendi panggul dan lutut mencapai $100^{\circ}$ dan $125^{\circ}$. Nilai Haris Hip Score 91 (excellent).

Bekas luka operasi kering tanpa tanda inflamasi. Penanda infeksi WBC 9,52 x 109/L (4,0-11,0), LED 14 mm/jam (12-18), CRP 1,86 mg/L $(<10)$. Dari evaluasi radiologis empat tahun pascatrauma didapatkan union dari subtrochanter femur seperti terlihat pada Gambar 3.
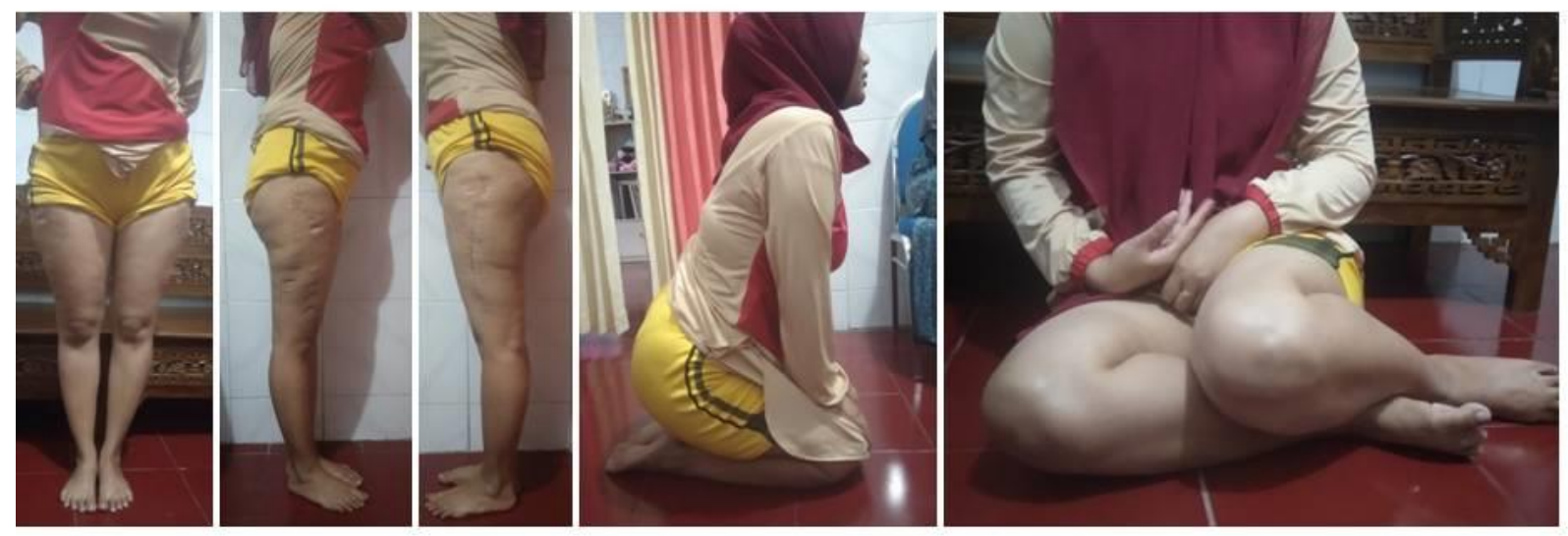

Gambar 2. Evaluasi klinis pasien setelah 4 tahun pascatrauma

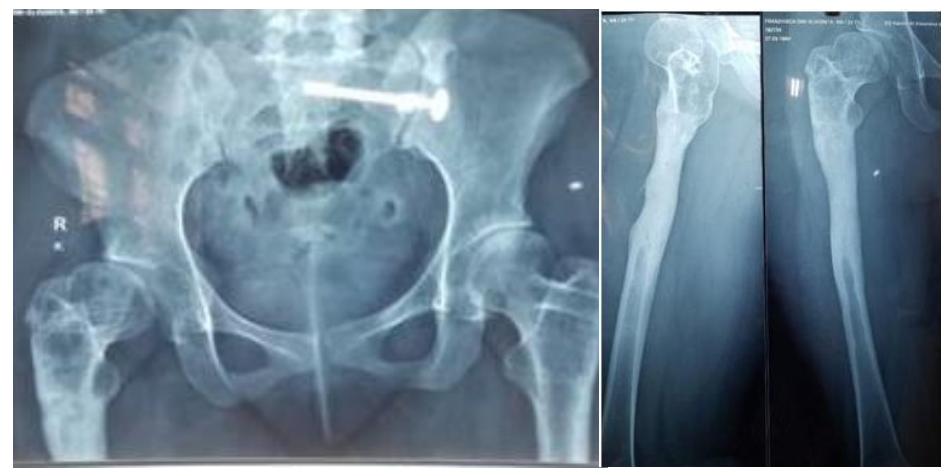

Gambar 3. Evaluasi radiologis 4 tahun pascatrauma 


\section{DISKUSI}

Infected non union adalah kondisi terjadinya kegagalan union tulang disertai dengan infeksi yang menetap lebih dari 6- 8 bulan. Infected non union dapat terjadi setelah patah tulang terbuka, setelah tindakan open reduction and internal fixation (ORIF), atau merupakan sequele dari chronic hematogenous osteomielitis. ${ }^{7}$

Prevalensi infeksi tulang pada operasi elektif kasus patah tulang tertutup berkisar antara 1\%-5\%, sedangkan pada kasus patah tulang terbuka mencapai 3\%-50\% bergantung dengan derajat keparahannya. ${ }^{2}$

Infeksi tulang kronis merupakan kasus yang mahal, sulit diterapi dan hasilnya seringkali tidak memuaskan. ${ }^{1}$ Walaupun sudah dengan berbagai kemajuan teknik operasi dan obat-obatan, rekurensi infeksi tulang masih 20\%-30\%. ${ }^{8}$ Infeksi mempersulit tercapainya fiksasi yang stabil dan menghambat proses penyembuhan. ${ }^{9}$

Proses penyembuhan terjadi jika aktivitas bakteri terkontrol, kondisi vaskularisasi pada daerah fraktur dalam kondisi baik, fiksasi stabil, soft tiusse coverage baik, dan manajemen defek tulang/bone graft adekuat. $^{7}$

Kondisi pasien juga mempengaruhi proses penyembuhan. Sebagaimana penelitian Cierny-Mader pada klasifikasi osteomielitis, terdapat faktor lokal dan sistemik pasien yang mempengaruhi proses penyembuhan. Faktor lokal antara lain berupa edema, kondisi vaskularisasi, kebiasaan merokok, dan neuropati. Sedangkan faktor sistemik antara lain kondisi yang menggangu sistem imun seperti neoplasma, gagal organ, diabetes, usia, dan malnutrisi. ${ }^{10}$

Pada kasus ini, pasien pada awalnya menjalani prosedur fiksasi eksternal femur temporer sebagai tindakan damage control. Fiksasi segera pada pasien politrauma dapat menurunkan morbiditas dan mortalitas, memudahkan perawatan, dan mencegah berbagai komplikasi. ${ }^{11}$ Akan tetapi penggunan fiksasi eksternal temporer sebelum fiksasi definitif meningkatkan resiko terjadinya infeksi pascaoperasi, terutama bila pin tract berdekatan atau melewati area operasi definitif. ${ }^{12}$ Walaupun demikian, beberapa penelitan lain menyanggah hal ini dan menunjukkan tidak ada korelasi antara pemasangan fiksasi eksternal temporer dengan angka infeksi post operatif. ${ }^{13}$

Sampai saat ini tidak ada protokol tunggal penanganan infected non union femur yang digunakan secara luas. ${ }^{2}$ Pada prinsipnya terdapat dua strategi yaitu teknik satu tahap atau dua tahap. ${ }^{14}$

Pada teknik satu tahap, semua tindakan debridement, fiksasi tulang dan manajemen defek dilakukan dalam satu kali operasi. Angka union untuk semua prosedur satu tahap yang pernah dipublikasikan 
bervariasi antara 70\%-100\% dan rekurensi infeksi berkisar 0\%- 55\%. Sedangkan pada teknik operasi dua tahap tindakan dibagi dua yaitu tahap pertama adalah debridement dan pemberian antibiotik, setelah kondisi bebas infeksi, dilakukan operasi tahap kedua untuk fiksasi atau manajemen defek. Presentasi union pada prosedur dua tahap ini bervariasi antara 66\%-100\% dan rekurensi infeksi rekunen berkisar 0\%$60 \% .^{14}$

Pada tahum 1986, Lautenbach mempublikasikan teknik pemberian antibiotik konsentrasi tinggi secara lokal pada infeksi total hip replacement. ${ }^{3}$ Teknik ini kemudian digunakan pada tatalaksana osteomielitis pascatrauma., ${ }^{3,15}$ Teknik Lautenbach merupakan sistem irigasi tertutup menggunakan selang double lumen yang diletakkan pada intramedularry canal. Antibiotik konsentrasi tinggi diberikan melalui selang dan dikuti dengan drainase. Sistem irigasi ini dipertahankan rata-rata selama tiga minggu. ${ }^{3}$

Johnson pada tahun 2012 memodifikasi teknik ini pada kasus infected non union clavicula. Karena medullary canal clavicula yang sempit, Johnson meletakkan selang di luar medullary canal pada daerah fraktur. Tulang difiksasi dengan fiksasi eksternal. Pada modifikasi ini, antibiotik diberikan selama 7 hari dan dilanjutkan dengan antibiotik oral. ${ }^{4}$
Teknik Lautenbach kebanyakan diikuti dengan operasi tahap kedua untuk fiksasi tulang, karena penggunaan fiksasi internal ataupun eksternal sulit dilakukan dengan selang yang masih berada di dalam medullary canal. ${ }^{3}$ Protokol tatalakasana infected non union femur dua tahap juga dipublikasikan oleh Ueng et al, 1999. ${ }^{16}$ Pada teknik ini, pemberian antibiotik lokal dilakukan pada saat operasi tahap pertama melalui implantsi antibiotic beads bersamaan dengan debridement dan pemasangan fiksasi eksternal. Operasi tahap kedua dilakukan 2-6 minggu kemudian untuk implantasi bone graft dan eksternal fiksaasi dipertahankan sampai union yang dicapai dalam waktu 7-15 bulan. ${ }^{16}$

Pada kasus ini, penulis awalnya mencoba mempertahankan implan ABP sebagai internal fiksasi dan hanya melakukan debridement, pemberian bone graft, dan antibiotik sistemik. Namun cara ini tidak berhasil dan berakhir dengan fixation failure.

Digunakan teknik operasi satu tahap yang terdiri dari implant removal, debridement baik pada kortek maupun medulla, bone graft, eksternal fiksaasi defintif, dan pemberian antibiotik lokal melalui modifikasi Lautenbach. Dua selang drain digunakan sebagai jalur pemberian dan drainase antibiok lokal dengan konsentrasi tinggi. Pemberian antibiotik lokal dilakukan selama seminggu. Dalam 
waktu 16 bulan, tanda infeksi hilang dan kalus yang terbentuk cukup kuat sehingga fiksasi eksternal dapat dilepas. Hasil tersebut tidak jauh berbeda dengan hasil pada protokol dua tahap yang dilakukan oleh Ueng, 1999. ${ }^{16}$ Operasi satu tahap mempersingkat waktu rawat inap dan memudahkan pasien untuk segera mobilisasi. ${ }^{9}$

Fiksasi eksternal femur merupakan pilihan fiksasi femur yang paling banyak memberikan komplikasi $^{17}$ dan tidak nyaman bagi pasien. ${ }^{9}$ Namun dibanding internal fiksasi, fiksasi eksternal meminimalkan permukaan implan yang terpapar pada jaringan infeksi. Implan orthopaedi merupakan permukaan avaskuler yang menjadi tempat kolonsasi patogen. ${ }^{10}$ Implan yang dipertahankan pada kondisi infeksi aktif menyebabkan bakteri 1000 kali lebih resisten dan infeksi akan kambuh bila antibiotik dihentikan. ${ }^{9}$ Angka union dengan implan yang dipertahankan pada kasus infected non union hanya mencapai $68 \% .^{18}$

Kekhawatiran lain yang timbul pada penggunaan fiksasi eksternal adalah kestabilan fiksasi yang tidak rigid. Pada area subtrochanter, fiksasi yang dipilih harus dapat menetralisir deforming force yang besar. Terlebih lagi pada kasus infeksi, stabilitas menjadi faktor penting karena stabilitas fragmen tulang secara signifikan menurunkan angka infeksi dan meningkatakan peluang union. ${ }^{9}$

Efikasi penggunaan fiksasi eksternal untuk fiksasi fraktur proximal femur sebenarnya sudah lama dipublikasikan sejak 1950 pada tatalaksana fraktur pertrochanter femur. ${ }^{19}$ Pada kasus fraktur subtrochanter femur, penelitian Dhal \& Siggh pada 1996 secara khusus menunjukkan kemampuan fiksasi eksternal untuk stabilisasi fraktur subtrochanter tanpa menimbulkan komplikasi yang berarti. $^{20}$ Sebanyak 51 pasien dengan subtrochanter femur yang difiksasi dengan eksternal fiksaasi, seluruhnya union dalam waktu rata-rata 6 bulan. $^{20}$ Pada negera berkembang dengan keterbatasan sumber dayanya, fiksasi eksternal seringkali menjadi pilihan fiksasi definitif. ${ }^{6}$

Penggunaan fiksasi eksternal femur pada kasus ini menghasilkan ruang gerak sendi lutut dan panggul yang fungsional tanpa adanya tanda-tanda rekurensi infeksi. Hal serupa juga didapatkan pada penelitian Ueng et al 1999 yang menggunakan eksternal fikasi sebagai fiksasi definitif pada femur. Melalui program rehabilitasi yang baik, rata-rata dapat mencapai fleksi lutut hingga $100^{\circ} .{ }^{16}$

Temuan lain yang didapatkan selama perawatan pada kasus ini adalah munculnya subluksasi sendi panggul kanan selama penggunaan fiksasi eksternal. Hal ini bisa jadi adalah akibat malalignment yang 
cenderung valgus. Akan tetapi, kondisi ini tidak banyak berdampak pada keluhan klinis pasien. Realignment osteotomy kemungkinan dapat memperbaiki permasalahan ini, akan tetapi tindakan osteotomi pada pasien ini tentu akan lebih sulit dan memiliki potensi komplikasi lebih besar karena riwayat infeksi dan non union sebelumnya. Pasien saat ini merasa puas dan memilih untuk tidak dilakukan tindakan selama tidak mengganggu aktivitas kesehariannya.

\section{KESIMPULAN DAN SARAN}

Fiksasi eksternal definitif dan modifikasi teknik Lautenbach dalam satu tahap operasi dapat menjadi salah satu pilihan terapi pada kasus infected non union subtrochanter femur.

Diperlukan penelitian dengan sampel yang adekuat dan metode yang terstruktur untuk memvalidasi dan menyempurnakan protokol terapi ini.

\section{REFERENSI}

1. Sanders J, Mauffrey C. Long Bone Osteomyelitis in Adults: Fundamental Concepts and Current Techniques. Hak DJ, Stahel PF, eds. Orthopedics. 2013; 36(5):368-375.

2. Walter G, Kemmerer M, Kappler C, Hoffmann R. Treatment Algorithms for Chronic Osteomyelitis. Dtsch Aerzteblatt Online. 2012; 109(14):257264.

3. Hashmi MA, Norman P, Saleh M. The management of chronic osteomyelitis using the Lautenbach method. J Bone
Joint Surg Br. 2004; 86-B(2):269-275.

4. Johnson B, Thomas P, McClelland D. Modified Lautenbach technique in the treatment of an open infected nonunion of the clavicle-a case report. Acta Orthop. 2012; 83(3):314-316.

5. Haidukewych GJ, Langford J. Subthrochanteric Fractures. In: Bucholz RW, Heckman JD, CourtBrown CM, Tor, eds. Rockwood and Green's Fracture in Adult. 7th ed. Philadelphia: Lippincott William \& Wilkins; 2010:1643-1654.

6. Tuttle MS, Smith WR, Williams AE, et al. Safety and Efficacy of Damage Control External Fixation Versus Early Definitive Stabilization for Femoral Shaft Fractures in the Multiple-Injured Patient. J Trauma Inj Infect Crit Care. 2009; 67(3):602-605.

7. Jain AK, Sinha S. Infected nonunion of the long bones. Clin Orthop Relat Res. 2005; (431):57-65.

8. Conterno LO, da Silva Filho CR. Antibiotics for treating chronic osteomyelitis in adults. In: Conterno LO, ed. Cochrane Database of Systematic Reviews. Chichester, UK: John Wiley \& Sons, Ltd; 2009.

9. Prasarn ML, Ahn J, Achor T, Matuszewski P, Lorich DG, Helfet DL. Management of infected femoral nonunions with a single-staged protocol utilizing internal fixation. Injury. 2009; 40(11):1220-1225.

10. Schmitt SK. Osteomyelitis. Infect Dis Clin North Am. 2017; 31(2):325-338.

11. Kobbe P, Micansky F, Lichte P, et al. Increased morbidity and mortality after bilateral femoral shaft fractures: myth or reality in the era of damage control? Injury. 2013; 44(2):221-225.

12. Shah CM, Babb PE, McAndrew CM, et al. Definitive plates overlapping provisional external fixator pin sites: is the infection risk increased? J Orthop Trauma. 2014; 28(9):518-522.

13. Laible C, Earl-Royal E, Davidovitch R, Walsh M, Egol KA. Infection After Spanning External Fixation for High- 
Energy Tibial Plateau Fractures: Is Pin Site-Plate Overlap a Problem? J Orthop Trauma. 2012; 26(2):92-97.

14. Struijs PAA, Poolman RW, Bhandari $M$. Infected Nonunion of the Long Bones. J Orthop Trauma. 2007; 21(7):507-511.

15. Caesar BC, Morgan-Jones RL, Warren RE, Wade RH, Roberts PJ, Richardson JB. Closed double-lumen suction irrigation in the management of chronic diaphyseal osteomyelitis. J Bone Joint Surg Br. 2009; 91-B(9):1243-1248.

16. Ueng SW, Wei FC, Shih $\mathrm{CH}$. Management of femoral diaphyseal infected nonunion with antibiotic beads local therapy, external skeletal fixation, and staged bone grafting. J Trauma. 1999; 46(1):97-103.

17. Ramseier LE, Janicki JA, Weir S, Narayanan UG. Femoral Fractures in Adolescents: A Comparison of Four Methods of Fixation. $J$ Bone $J t$ Surgery-American Vol. 2010; 92(5):1122-1129.

18. Rightmire E, Zurakowski D, Vrahas M. Acute Infections After Fracture Repair. Clin Orthop Relat Res. 2008; 466(2):466-472.

19. Kazemian GH, Manafi AR, Najafi F, Najafi MA. Treatment of intertrochanteric fractures in elderly highrisk patients: Dynamic hip screw vs. external fixation. Injury. 2014; 45(3):568-572.

20. Dhal A, Singh SS. Biological fixation of subtrochanteric fractures by external fixation. Injury. 1996; 27(10):723-731. 